\title{
Mixed plutonium-uranium carbide fuel in fast breeder test reactor
}

\author{
P RODRIGUEZ \\ Indira Gandhi Centre for Atomic Research, Kalpakkam 603 102, India
}

\begin{abstract}
This paper describes the development of the indigenous plutonium-uranium mixed carbide nuclear fuel for the fast breeder test reactor. The fuel has performed satisfactorily and produced, for the first time in our country, nuclear electricity from a fast reactor. The experience and knowledge gained in the fuel development has provided great confidence for undertaking a programme on utilization of fast reactor technology for power production.
\end{abstract}

Keywords. Nuclear fuel; fast reactors; carbides.

\section{Introduction}

Among the nuclear reactor systems, the fast reactors (nuclear reactors where fission reaction is induced by fast neutrons) offer a number of advantages over the thermal reactor systems (where fission is induced by slow neutrons). The fast reactors are energy efficient, environment-friendly and safe. In the context of our country, the fast reactors have a special significance in that, they would help in greatly enhancing utilization of the uranium reserves, in addition to being the most attractive route for the utilization of the vast thorium resources in our country (Rodriguez and Bhoje 1998; Rodriguez and Lee 1998). The indigenous development of the fast reactor technology is the primary mission of the Indira Gandhi Centre for Atomic Research (Rodriguez 1996).

To a materials scientist, the nuclear fuel used in the fast reactor is a subject of challenging and interesting research. Fast reactors operate in regimes which are quite hostile to the fuel and structural materials. They operate at high temperatures and due to high specific and linear power ratings; the temperature gradients inside the fuel are also significant. Thus, the behaviour of the fuel during reactor irradiation is an important aspect which critically influences the choice of the fuel.

A mixed oxide of uranium and plutonium (solid solution of $\mathrm{UO}_{2}-\mathrm{PuO}_{2}$ with $\mathrm{Pu} / \mathrm{U}$ ratio of $\sim 0.2$ ) is a fuel of popular choice for the fast breeder power reactors. This fuel is a ceramic material with a high melting point and excellent chemical stability. The oxide fuel has been irradiated to very high levels of 'burn-up' in various fast reactors. A burn-up of 20 atom\% (fission of 20 atoms of heavy metal for 100 atoms initially present) has been achieved in fast reactors (Legget and Walters 1993). This corresponds to an energy production of $\sim 200000 \mathrm{MWd} / \mathrm{t}$ of the fuel. The reference fuel for the prototype fast breeder reactor being developed at IGCAR is thus an oxide fuel, with $\mathrm{Pu} /(\mathrm{U}+\mathrm{Pu})$ of $\sim 0.2$.
The story of the nuclear fuel for fast breeder test reactor (FBTR) is rather unique. Like in all experimental fast reactors, because of the small size of the core, the neutronic considerations dictated that the FBTR fuel should have a high enrichment in fissile content. Initially, a U-Pu mixed oxide fuel rich in $\mathrm{Pu}$ was considered for use as the FBTR fuel. However, tests carried out on this fuel indicated the possibility of severe fuel-coolant interaction in the event of liquid sodium coming into contact with the oxide fuel rich in plutonium. Further, during fabrication, it was not possible to meet all the specifications of the fuel simultaneously, viz. O/M ratio, pellet density and single phase microstructure. In view of these difficulties, the Pu-rich fuel option for FBTR was not pursued further. Subsequently, the possibility of using a mixed oxide with $\mathrm{Pu} /(\mathrm{U}+\mathrm{Pu})$ of $\sim 0.3$ and uranium enriched to about $85 \%$ in $\mathrm{U}^{235}$ was looked into. However, difficulties in obtaining enriched uranium from other countries forced us to abandon the idea of using mixed oxide as fuel for FBTR. We were thus faced with a situation of having to look for an alternate fuel for the reactor. This led us to the choice of $\mathrm{U}, \mathrm{Pu}$ mixed carbide as the fuel for FBTR.

As a fast reactor fuel, the mixed carbide has many advantages over the oxide fuel (table 1). The high metal atom density and the high thermal conductivity are important aspects. The carbide fuel is a better breeder than an oxide fuel. Further, because of the high thermal conductivity, the temperatures as well as the temperature gradients in the carbide fuel are much lower than in the case of oxide fuels. Typically, the oxide fuel has a centreline temperature of $>2000^{\circ} \mathrm{C}$, whereas the temperatures are in the range of $1500^{\circ} \mathrm{C}$ for a carbide fuel. The lower temperatures lead to a significant reduction in the migration of the fuel constituents as well as the fission products.

Despite these advantages, the use of mixed carbide fuel posed many challenges. The carbide is pyrophoric 
in nature and thus has to be fabricated and handled in an inert atmosphere. Very little physicochemical or thermochemical data were available in literature for the mixed carbide with a $\mathrm{Pu} / \mathrm{U}+\mathrm{Pu}$ ratio of about 0.7 , which was the composition chosen for the initial core of FBTR. The safety authorities had to be satisfied that the fuel could be operated safely without the centreline temperature of the fuel, crossing the melting point. These challenges have been met quite satisfactorily and the fuel has reached a burn-up of $\sim 50,000 \mathrm{MWd} / \mathrm{t}$, which happen to be the highest burn-up seen by a nuclear fuel, in our country. This paper highlights the studies carried out on the carbide fuel at BARC and IGCAR to provide the input data for the fuel design for FBTR.

\section{Thermophysical properties}

The most crucial information required for the fuel designer is the power levels up to which the fuel can be operated. This demands a knowledge of the thermal conductivity as well as the melting point of the fuel. The mixed carbide fuel melts peritectically. Data were not available in the literature for the melting point of the fuel of the chosen composition. The melting point was measured to be $1875^{\circ} \pm 25^{\circ} \mathrm{C}(2148 \mathrm{~K})$ at Radiometallurgy Division, BARC (Sengupta et al 1986).

While the melting point provides a limit for the centreline temperature at which the fuel can be operated, the thermal power which can be extracted from the fuel is determined by the thermal conductivity of the fuel. Again, the thermal conductivity data on the fuel were not available in literature; these were measured both for the initial composition as well as subsequent composition for the second core $(\mathrm{Pu} / \mathrm{U}+\mathrm{Pu}=0.55)$ at $\mathrm{BARC}$ and IGCAR. This measurement employs a laser flash technique in which the laser beam impinges on the front surface of a thin sample disk and the transient temperature response at the rear surface of the sample is measured by employing a sensitive infrared detector, coupled to a high speed data processing unit. It must be noted that

Table 1. Fast reactor fuels-A comparison.

\begin{tabular}{|c|c|c|c|}
\hline Fuel* & $\begin{array}{l}\text { Density } \\
(\mathrm{g} / \mathrm{cc})\end{array}$ & $\begin{array}{l}\text { M.P. } \\
\text { (deg. K) }\end{array}$ & $\begin{array}{l}\text { Thermal } \\
\text { conductivity } \\
\left(\mathrm{W} . \mathrm{cm}^{-1} \cdot \mathrm{K}^{-1}\right)\end{array}$ \\
\hline $\mathrm{MO}_{2}$ & 11.00 & 2950 & $0.022(1373 \mathrm{~K})$ \\
\hline MC & 12.95 & 2700 & $\begin{array}{l}0.17-0.22 \\
(1073-1473 \mathrm{~K})\end{array}$ \\
\hline MN & 13.53 & 3050 & $\begin{array}{l}0 \cdot 17-0 \cdot 22 \\
(1073-1473 \mathrm{~K})\end{array}$ \\
\hline $\mathrm{U}-15 \mathrm{Pu}-10 \mathrm{Zr}$ & $14 \cdot 13$ & 1426 & $\begin{array}{l}0.18-0.25 \\
(673-1073 \mathrm{~K})\end{array}$ \\
\hline
\end{tabular}

${ }^{*} \mathrm{M}=0.8 \mathrm{U} / 0.2 \mathrm{Pu}$ the main experimental apparatus including the furnace etc is placed inside an inert atmosphere glove box while the laser and the electronics modules are placed outside the glove box. Figure 1 shows typical results of the thermal conductivity measurements carried out at BARC on the Mark I and Mark II fuels.

\section{Out-of-pile simulation}

Even with the availability of the melting point and the thermal conductivity data, the picture of fuel behaviour inside the pin during reactor operation is incomplete since there is a small but significant gap between the fuel and the stainless steel clad in the initial stages. This small gap (filled by helium) results in higher temperatures of operation in the initial phase till the fuel restructures and expands and touches the cladding, thereby establishing direct heat transport. In order to operate the nuclear reactor, we had to satisfy the safety authorities that at the proposed power ratings, the fuel could restructure fairly quickly and establish the contact with the cladding, bringing down the temperatures inside the fuel. Besides, we had to establish that the centreline temperatures in the fuel even in the initial stages would

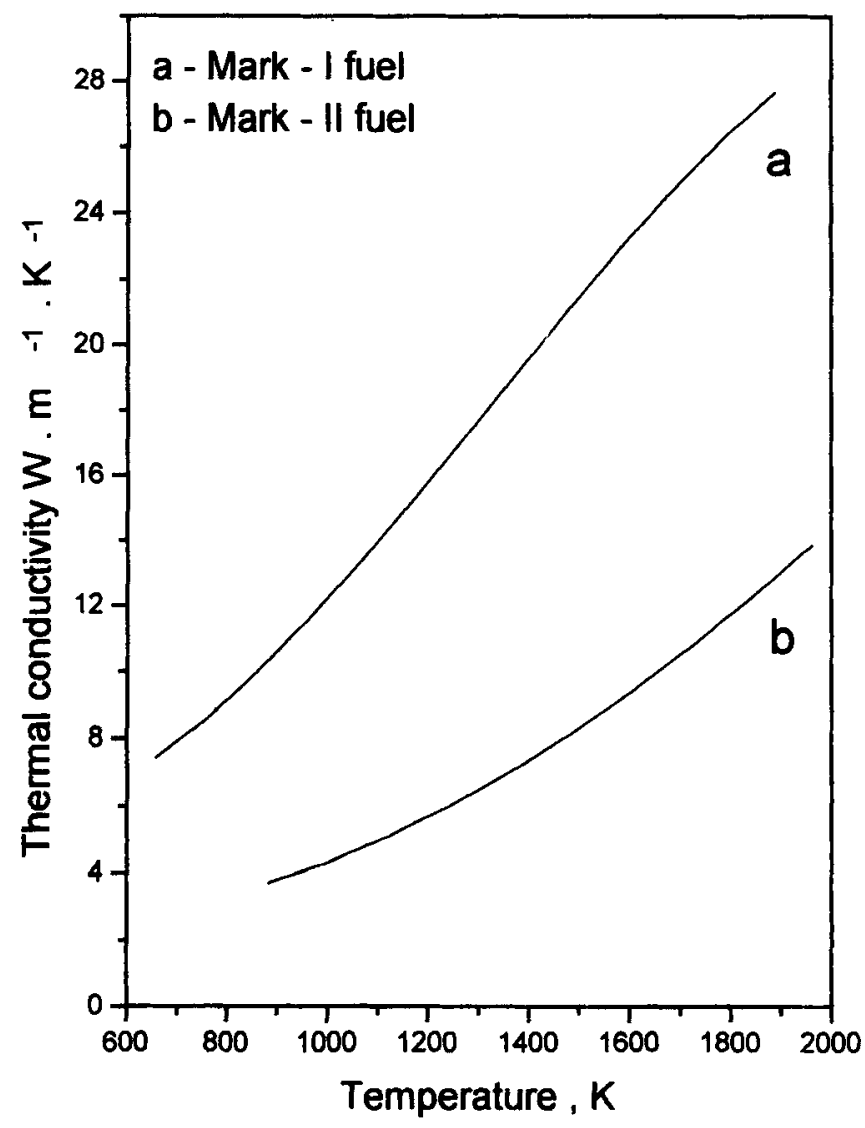

Figure 1. Thermal conductivity of the FBTR fuel with $\mathrm{Pu} /(\mathrm{U}+\mathrm{Pu})$ ratio 0.7 and 0.55 (the fuel contains up to $20 \mathrm{vol} \%$ of sesquicarbide). 
not cross the melting point. Thus experiments to study this aspect of the fuel behaviour were conducted at IGCAR in an 'Out-of-pile simulation apparatus' specially set up for this purpose. In this experiment, a column of the fuel pellet was heated to high temperatures by passing electric current through the pellet. Thermal gradients were adjusted by suitably modifying the flow of helium gas around the pellet. In this way, the thermal performance of the fuel at various power ratings was simulated in the laboratory. It is significant to note that these experiments were also conducted in an inert atmosphere glove box. A typical micrograph of the fuel pellet tested out-of-pile to a linear heat rating of $320 \mathrm{~W} / \mathrm{cm}$ is given in figure 2 (Antony et al 1997). There is no evidence of fuel melting in the centre of the fuel clad. The fuel-clad gap also was found to be closed within a few hours. These data were instrumental in obtaining permission from the safety authorities for operating the reactor at the linear heat rating of $320 \mathrm{~W} / \mathrm{cm}$. This experimental facility is now being upgraded for similar simulation experiments with other fuel materials including oxide fuels.

\section{Carbon potential of mixed carbide fuel}

The fuel being carbon rich, the possibility of carburization of the stainless steel cladding was examined through experimentation and modelling. The carbon potential of the FBTR fuel was measured by a gas equilibration technique in which the fuel was equilibrated with hydrogen gas and the methane/hydrogen ratio in the gas

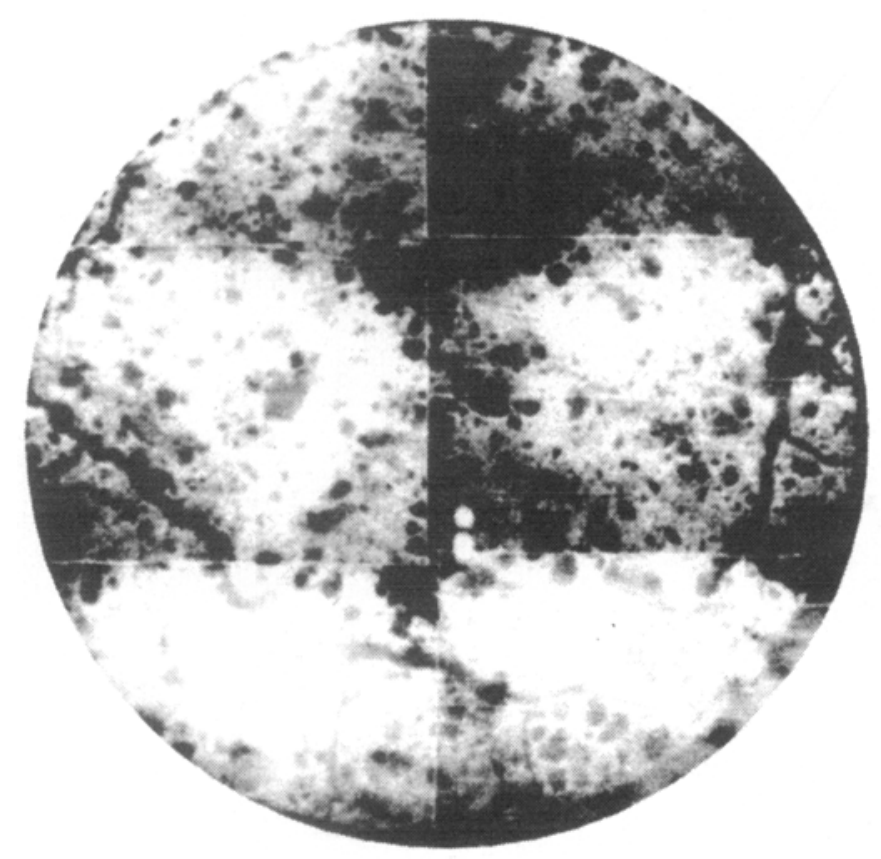

Figure 2. Photomicrograph of radial section of the FBTR fuel pellet $[\mathrm{Pu} /(\mathrm{U}+\mathrm{Pu})=0.7]$ after out-of-pile heating at $320 \mathrm{~W} / \mathrm{cm}$. phase was measured to arrive at the carbon potential of the fuel (Anthonysamy et al 1995). These data along with data on the carbon potential of the stainless steel helped us to conclude that the fuel will indeed be compatible with the stainless steel cladding (figure 3 ). Experiments in which the carbide fuel pellet was maintained in close contact with stainless steel and sodium over a long period of time, also confirmed the compatibility with the cladding material as well as sodium (Ganguly and Sengupta 1988). These experiments gave confidence to us in deploying the carbide fuel in FBTR.

\section{Fabrication of the mixed carbide fuel for FBTR}

As mentioned above, no experience was available in our country as well as other countries on the fabrication and irradiation of carbide fuel with high plutonium content. The specifications of the fuel for FBTR had to be therefore worked out based on the limited data available in the literature on the thermophysical properties, the data on melting point and thermal conductivity generated in our laboratories, and chemical modelling of the phase behaviour, vapour pressures, carbon potential and other properties of the $\mathrm{U}-\mathrm{Pu}-\mathrm{C}-\mathrm{N}-\mathrm{O}$ system (Anthonysamy et al 1995). The specifications of the FBTR fuel, listed in table 2, bring out the stringent quality control necessary in the fabrication of the fuel pellets. The fuel was fabricated in the Radiometallurgy Division at BARC (Ganguly et al 1986). It is to be noted here that the entire fabrication involving vacuum carbothermic reduction of the oxide at high temperatures, milling, tabletting, sintering and the subsequent examination of the pellets had to be carried out in inert atmosphere glove boxes, in view of the toxicity and the pyrophoricity

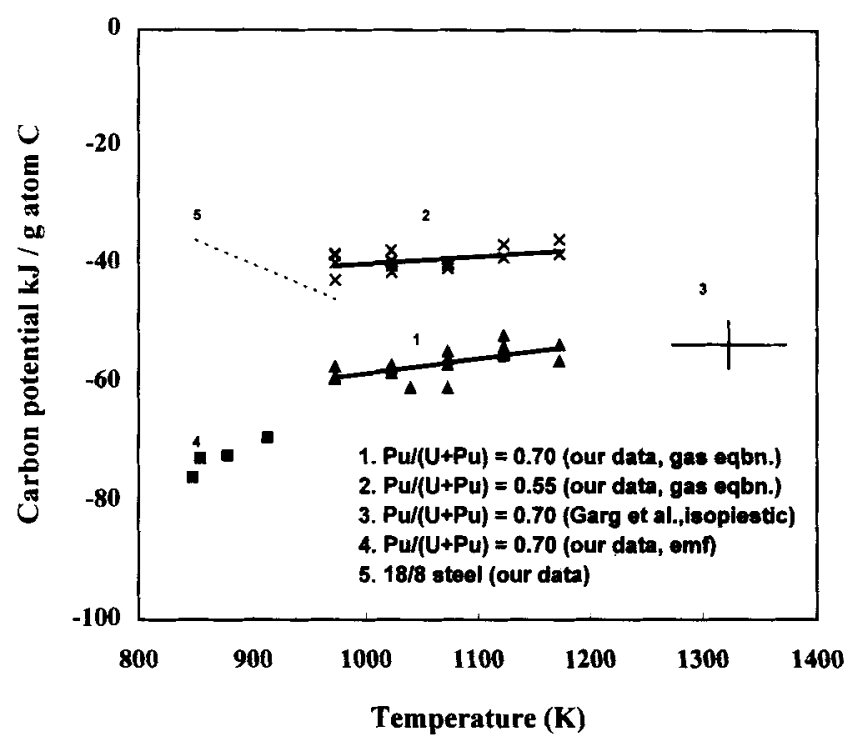

Figure 3. Carbon potential al plutonium, uranium mixed carbide fuels and stainless steel. 
Table 2. Specifications of $(\mathrm{U}, \mathrm{Pu}) \mathrm{C}$ fuel for FBTR.

\begin{tabular}{ll}
\hline Property & Specifications \\
\hline Plutonium content & $66.0 \pm 1.0 \mathrm{w} / \mathrm{o}$ \\
Plutonium + uranium & $\geq 94.0 \mathrm{w} / \mathrm{o}$ \\
Carbon & $5.05 \mathrm{max}$ \\
Oxygen & $\leq 0.6 \mathrm{w} / \mathrm{o}$ \\
Oxygen + nitrogen & $\leq 0.75 \mathrm{w} / \mathrm{o}$ \\
$\mathrm{M}_{2} \mathrm{C}_{3}$ & 5 to $20 \mathrm{w} / \mathrm{o}$ \\
Impurities & $\leq 0.3 \mathrm{w} / \mathrm{o}$ \\
Free heavy metal & $\mathrm{Nil}$ \\
Total gas/g pellet & $0.1 \mathrm{cc} \mathrm{at} \mathrm{NTP}$ \\
Diameter & $4.18 \pm 0.04 \mathrm{~mm}$ \\
Height & $7 \mathrm{~mm} \mathrm{nominal}$ \\
Density & $90 \pm 1 \% \mathrm{~T} . \mathrm{D}$. \\
Linear mass & $1.67 \pm 0.04 \mathrm{~g} / \mathrm{cm}$ \\
\hline
\end{tabular}

of the material. The starting materials as well as the carbide produced were subjected to chemical analysis at different stages to confirm that the fuel indeed met the chemical specifications. The pellets were then sealed in stainless steel pins and constituted into the subassemblies. The production of hardware for the subassembly and the assembly of fuel into sub-assemblies were carried out by the Nuclear Fuel Complex.

\section{Post-irradiation examination}

It goes to the credit of the scientists and engineers involved in the design and the development of the FBTR fuel that the fuel has operated so far to a burn-up of $\sim 43,000 \mathrm{MWd} / \mathrm{t}$ without any pin failure. The burn-up targeted originally for this fuel was $25,000 \mathrm{MWd} / \mathrm{t}$, but

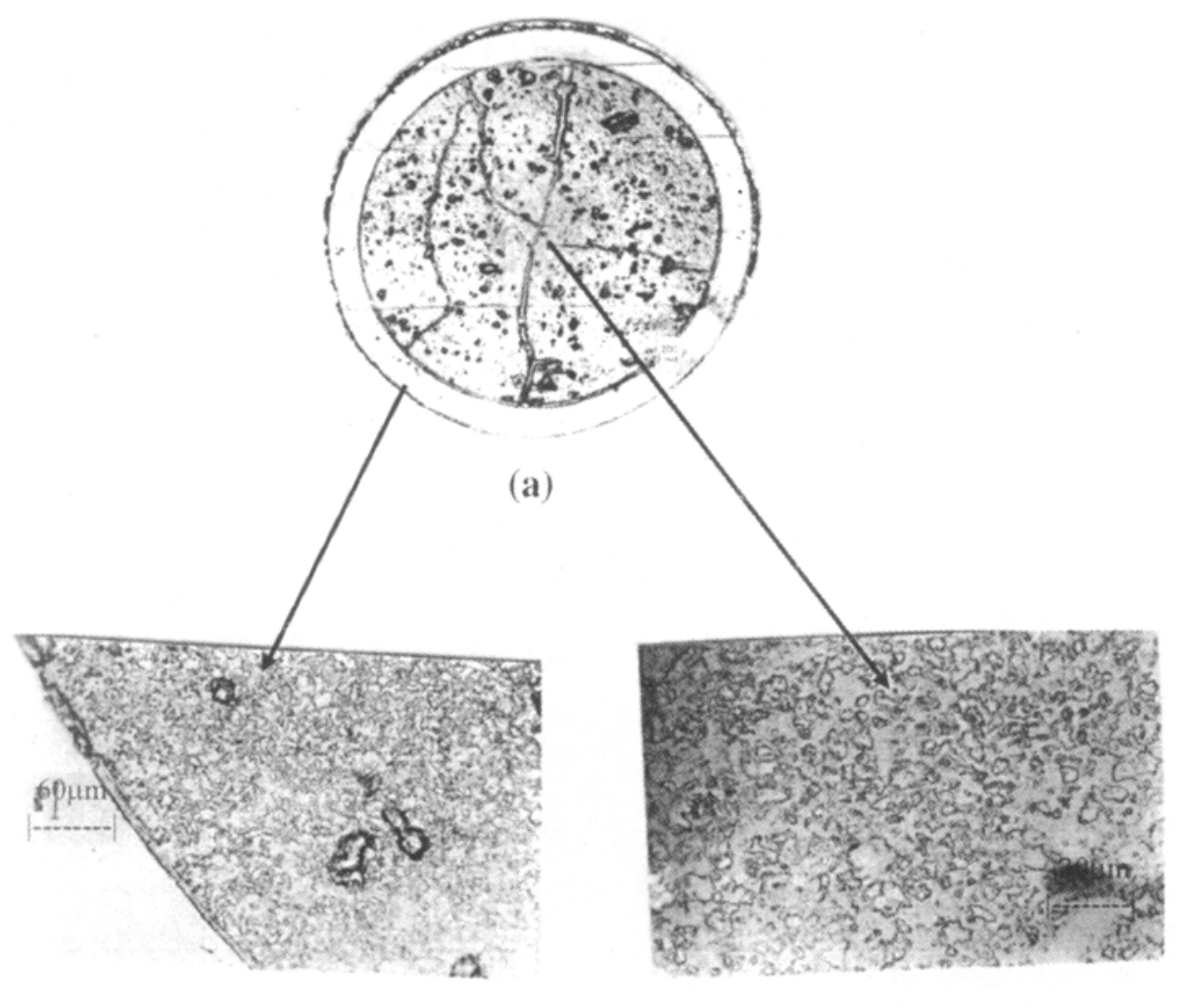

(b)

(c)

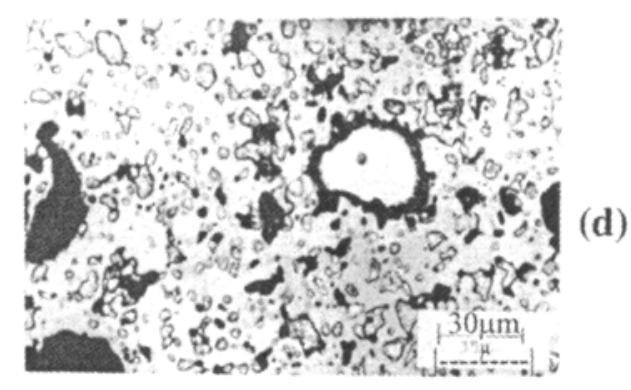

Figure 4. Photomicrographs showing etched structure of the fuel, irradiated to 25,000 $\mathrm{MWd} / \mathrm{t}$ burn-up (a, b, c) and a typical unirradiated fuel (d). 
the post-irradiation examination carried out on one fuel sub-assembly which was discharged at $25,000 \mathrm{MWd} / \mathrm{t}$, has given us confidence that the fuel may indeed be irradiated to burn-up levels higher than $50,000 \mathrm{MWd} / \mathrm{t}$.

The confirmation of the fuel behaviour and the feedback to the fuel designer are provided by the post-irradiation examination of the fuel discharge from the reactor. As a result of the reactor irradiation, the irradiated fuel is highly radioactive and therefore needs to be handled in 'hot cells', enclosures with thick concrete walls and special glass windows employing totally remote operations. For examining the carbide fuel, because of its pyrophoricity and the tendency to get oxidized, we had to convert the cells for operation in an inert (nitrogen) environment with stringent controls on oxygen and moisture levels. The post-irradiation examination of FBTR fuel was conducted in the Radiometallurgy Laboratory, IGCAR. Apart from dimensional measurements and $X$-radiography on the fuel which indicated that the swelling of the fuel was within limits, the examination of the microstructure of the fuel also indicated that the fuel had not undergone extensive restructuring or cracking (figure 4). Besides, sufficient fuel-clad gap was still found to exist thereby indicating that some more swelling could be safely accommodated without mechanical interactions between the fuel and the cladding. The post-irradiation examination campaign not only gave us confidence about burn-up levels which can be achieved safely with the FBTR fuel, but also gave us tremendous confidence in the handling of and experimentation with highly irradiated materials through remote operations.

\section{Fuel reprocessing}

After reaching the targeted burn-up, the carbide fuel has to be discharged from the reactor and reprocessed to recover the un-burnt uranium and plutonium for recycling. This again is a very challenging operation involving highly radioactive materials. The fuel has to be dissolved in nitric acid medium and then recovered by a process (called PUREX process) employing solvent extraction. Once again, no experience was available in the literature on reprocessing of the carbide fuel anywhere in the world. It is well known that the dissolution of the carbide fuel in nitric acid leads to the formation of a large number of organic compounds which may cause serious interference in solvent extraction steps, besides the reduction in the recovery of plutonium. We have now developed an electrochemical dissolution step for complete destruction of all the organic compounds (Palamalai et al 1991).

The extraction process for recovering plutonium also encounters difficulties in the case of fast reactor fuels, because of the high plutonium concentrations which leads to unique chemical problems. These were also studied through laboratory scale experiments which have provided us adequate data for finalizing the flowsheet for the solvent extraction process.

To qualify the flowsheet for FBTR fuel reprocessing as well as various specialized equipment which have to be developed for this purpose, a Lead Mini Plant is under construction at IGCAR. The experience obtained through the operation of this plant will provide inputs to the process to be adopted in the Fast Reactor Fuel Reprocessing Plant (FRFRP), which will ultimately handle the bulk of the irradiated fuel from FBTR.

\section{Conclusion}

It is thus seen that the entire 'fuel cycle' starting from fuel design to irradiation to reprocessing has added dimensions in the case of carbide fuel. Even though the choice of the fuel was thrust on us due to unavoidable circumstances, we have reasons to feel happy about the experience we have gained on the use of the carbide fuel. The fuel has behaved satisfactorily. The FBTR has, in fact, produced the first nuclear electricity from fast reactor to flow into the Indian Electricity grid. The carbide fuel cycle is thus a subject of immense satisfaction to all the scientists and engineers who have been involved in this project.

As mentioned in the introduction, the carbide fuel has many unique features as a ceramic fuel also, in that the fuel operates at low temperatures as compared to the oxide fuel and has high thermal conductivity, besides higher fissile atom density. These advantages can be effectively exploited in the effective utilization of the uranium resources in the country through breeding of plutonium. The experience gained from the FBTR is also significant for the future of the fast reactor programme in our country, since it provides a wider option for the choice of the nuclear fuel for the power reactors to follow.

\section{Acknowledgements}

The development of fast reactor technology is the primary mission of the Indira Gandhi Centre for Atomic Research. However, various facets of the fuel cycle of FBTR have been developed by the Bhabha Atomic Research Centre, Mumbai and the Nuclear Fuel Complex, Hyderabad, in addition to IGCAR. I have had the privilege of leading the fast reactor programme in the past six years, and I take this opportunity to acknowledge with thanks the contributions of various groups in the DAE units which have been responsible for the success of the programme.

\section{References}

Anthonysamy S, Ananthasivan K, Kaliappan I, Chandramouli V, Vasudeva Rao P R, Mathews C K and Jacob K T $1995 \mathrm{~J}$. Nucl. Mater. 22320 
Antony M P, Daniel J and Mathews C K 1997 Nucl. Technol. 117299

Ganguly C and Sengupta A K 1988 J. Nucl. Mater. 158159

Ganguly C, Hegde P V, Jain G C, Basak U, Mehrotra R S, Majumdar S and Roy P R 1986 Nucl. Technol. 7259

Legget R D and Walters L C $1993 \mathrm{~J}$. Nucl. Mater. 20423

Palamalai A, Rajan S K, Chinnuswami A, Sampath M, Verghese P K, Ravi T N, Raman V R and Balasubramanian G R 1991 Radiochimica Acta $\mathbf{5 5} 29$
Rodriguez P 1996 Fast breeder reactor: The route to India's energy security and the mission of Indira Gandhi Centre for Atomic Research-The 12th Professor Brahm Prakash Memorial Lecture, Indian Institute of Metals, Bangalore Chapter Rodriguez P and Bhoje S B 1998 Energy 23629

Rodriguez P and Lee S M 1998 Curr. Sci. 74317

Sengupta A K, Goswami G L, Garg S P, Sayi Y S, Radhakrishna $\mathrm{J}$ and Sood D D 1986 in Proc. seminar on fast reactor fuel cycle (Kalpakkam: IGCAR) p. 50 